\title{
Managerial Potential of Educational Organizations under Conditions of Network Interaction
}

\author{
https://doi.org/10.3991/ijet.v15i01.11333 \\ Nataliia N. Davydova ${ }^{(\varpi)}$, Evgeniy M. Dorozhkin, Vladimir A. Fedorov \\ Russian State Vocational Pedagogical University, Yekaterinburg, Russia \\ davydova_nataliia@bk.ru
}

\begin{abstract}
Development of new forms of labor self-organization is embodied in phenomena of distributed management and direct influence of personnel on realization and development of the organization's strategy. The article is devoted to studying of relations underlying the development of managerial potential of an educational organization under conditions of network interaction. The work involves activity, network, system-synergetic approaches and methods of comparative theoretical and methodological analysis, theoretical reconstruction of bases of development strategies of a modern educational organization's managerial potential under conditions of network interaction. Differences of the network and non-network managerial paradigms in education are described in detail. It was established that the managerial potential of educational organizations is actively realized in course of development of collectives' involvement into solving and realization of strategic and tactic tasks in conditions of activity of the scientificeducational network. It is demonstrated that development of the managerial potential of interaction participants is provided via creation of additional managerial roles and solving of super-functional managerial tasks, which allows to change the nature of the managerial labor. It is demonstrated that managerial potential of teachers' collectives can successfully developed in integrative management technologies based on a new methodology focused on development of involvement of network interaction into solving of organizational issues, solving of strategic and tactic tasks under conditions of systemic activity of the scientific-educational network.
\end{abstract}

Keywords-Scientific-educational network, unclassical forms of managerial activity, network and non-network managerial paradigms, managerial potential, development of managerial activity, network interaction.

\section{Introduction}

Changes in the socio-economic sphere taking place since the late $20^{\text {th }}$ century significantly influence transformation of contents and forms of the managerial activity. Development of new forms of labour self-organization is connected, first of all, with the distributed management phenomenon [1]. The revealed phenomenon speaks for development of new, unclassical forms of the managerial activity realization which reflect ability and readiness of organizations' personnel to take part in making and realization of 
managerial solutions. Development of the appropriate phenomenology points at necessity to regard an organization's collective as a special subject of the modern labour which possesses ability for self-organization and self-development. At the same time, basic approaches to defining, evaluation and development of collectives' managerial potential are still determined by the existing institutionalization of managerial labour. At present, these formalized mechanisms dialectically conflict with the needs of renovating socio-economical systems in developing of an initiative approach, flexibility and readiness to act under uncertainty conditions. The characterization of managerial potential as the basic resource of organizations competitiveness development belongs to new qualitative features of the managerial labour [2].

The use of the ideology of network interaction is promising for its implementation [3], [4]. In this regard, the aim of the study was to determine the possibilities of developing the management potential of the teams of educational organizations in the conditions of network interaction. The article includes a review of sources on the problem under study, a description of the methodology and research methods, including the consideration of activity, network and system-synergetic approaches and methods of comparative theoretical and methodological analysis, theoretical reconstruction of the bases of strategies for the development of management potential of teams in a network interaction. Among the main results of the study should be noted the definition of the main differences between the network and non-network management paradigm, directions of development of scientific and educational networks that affect the formation of the management potential of teams, the identification of the main management tools for the development of the management potential of network interaction participants.

\section{$2 \quad$ Literature Review}

The modern socio-economic conditions acts as the main factor of changing the content, nature, realization forms and the very essence of the managerial activity. These conditions require renovation of the managerial potential in developing socio-economical systems [5]. To recap, the managerial potential is regarded as a special object of development [6] and as an important source of organizations' strategic development [7]. According to UN Convention on the Protection and Promotion of the Diversity of Cultural Expressions [8], revelation, estimation and timely use of this resource is now a problem common to all mankind. Issues of studying of the managerial potential state were handled at varying times by Zaslavskaya T.I. [9], Parker S.K., Williams H. M. \& Turner N. [10], Nizhegorodtsev R.M. \& Reznik S.D. [11]. The conceptual diversity of approaches resulted in finding of contradiction between the approach to definition of the managerial potential as functional readiness of the personnel for solving of complicated tasks under conditions of increasing uncertainty [12], [13] and considering thereof as an indicator of the personnel institutional resource. This contradiction led to a shift of emphasis in scientific researches from the subject of development (managerial potential) to the object of development (state of the personnel). This contradiction was methodologically singled out but is not overpassed yet [14]. 
In this connection, the managerial potential of educational organizations as an important resource of realization of tasks and goals of the managerial activity in education in the post-industrial epoque is defined as the object of this study.

It's worth noting that the modern labour activity is ever increasingly developed as a joint activity [15], as the modern society of knowledge is developing as a network society [16], wherein information (knowledge) is freely distributed and developed releasing from hierarchical formats which restrain interaction and ability to form the general understanding in the joint activity. In this case, it is especially important to work at formation of the general understanding of complex situations, agreeing of actions of stockholders groups [17], [18]. Collectives strive not just to realize a system of externally set functions but also to exert essential influence on all processes flowing within the organization, both production and management related [19]. In new conditions, employees are partners in the organization and performing of a certain work [20]. Development of joint activity, uniting of employees' efforts in solving of common problems is connected with manifestation of development of democracy in social interaction. Development of interaction is expressed in a leader's impossibility to stay in the special position in relation to other workers, despite the fact they are his/her subordinates. The increasing social changes lead to development of new forms of managerial activity related to actual conditions of its realization (jointness, virtuality, network organization, flexibility), which is logical responses to challenges of the time [21], [22]. These new unclassical forms of the managerial activity realization principally differ from the nature of the classical managerial activity at solving of basic managerial tasks, as the managerial function and active managerial activity in this case is performed not by workers who have formal managerial duties (managers) but by other persons "anonyms" [22]-[24]. Moreover, growth of the role of informal communication is characteristic for unclassical forms of managerial activity, due to the fact that in organizations and in the communicative (network) space forces of special influence on strategic solutions are formed around the organization. A number of authors consider among such "forces of influence" informal talks and formally unacknowledged but widely discussed themes and fields of managerial solutions which create special dynamics of institutionalization of solutions proposed not by those who are in charge for them according to their position in the organization [25].

The next difference of unclassical forms of managerial activity is possibility of direct influence on an entity's strategy by employees of various level through the "strategic intervention" technique [26], which is expressed in a worker's ability to influence the system of ideas about strategically significant circumstances. Actually, these employees go beyond their functional space and their powers, widen the apprehension of the object of their own management and occur to be in a vague position, akin to the top manager's position in terms of its status. They become "managers of senses" [27], [28] in other people's activity, that is, they perform a real managerial activity by organizing other workers for realization of goals significant for the entity. Work in spontaneously emerging scientific-educational networks is a basis of such influence, while arrangement of strategic conversations and strategic sessions is a mechanism thereof [29], [30]. Strategic sessions are regarded as an important form of joint activity in course whereof apprehensions are altered and solutions are made. The main mechanism of a strategic 
session is counteraction and tension handling, and it is the employees mastering this mechanism who make the decisive contribution into management of the organization and other employees' activity.

One more difference of unclassical forms of managerial activity, in our opinion, is elevated readiness of top managers to rely on a position generated on lower levels. For instance, W. Shi and colleagues [31] found that there is a considerable number of "structural fails" in modern organizations, which makes linear and mid-level managers to independently liquidate these disruptions of the "managerial field", while top managers have to hear such "prompts from the bottom" at formation and realization of decisions [32].

Thus, modern (unclassical) forms of managerial activity are connected with increasing of the role of network communication and a special sense-bearing nature of managerial effect, which changes the very mechanism of realization of managerial functions from institutionally arranged to a combined functionally self-organizing one. The modern managerial activity should be regarded rather than translation of senses promoted over freely organized networks in the management space [33]. The object of this study is relations lying in the basis of development of the managerial potential of an educational organization under network interaction conditions. It is development of the managerial potential which can be regarded as an important resource of growth of a modern organization's activity efficiency which operates under conditions of ever-increasing competitiveness and uncertainty. We believe that the managerial potential of an educational organization's teams can successfully develop in integrative management techniques based on the new methodology oriented on development of involving of educational organizations' teams into solving of organizational issues and solving of strategic and tactic tasks under conditions of systemic activity of a scientific-educational network. In this connection, determination of possibilities of development of the managerial potential of educational entities' collectives under conditions of network interaction becomes the goal of this study.

\section{Methods}

\subsection{Research design}

The study used activity, network and system-synergetic approaches. The detail approach focuses on the leading role of activities in the process of development of the management potential of the teams participating in the interaction. Taking into account the main provisions of the activity approach, it is possible to assess the state of the scientific and educational network, to identify possible options for its development. This will allow you to make a choice and developed the satellite development program and management capacity in accordance with characteristics of the community of interests and differences in the positions of the participants of the interaction.

The network approach sets out certain principles for the study of interacting sets of individuals, groups, institutions, etc., which can have several roles (functional values) at certain times, or play different roles at different times. Within the framework of the 
network approach, it is possible to revise the roles of interaction subjects. The systemsynergetic approach allows building inter-system relations on the basis of interaction and mutual enrichment of network participants, to choose the most rational structures for building network interaction and development of management potential of teams. On the basis of the above-mentioned approaches in accordance with the goal, the methods of comparative theoretical and methodological analysis, theoretical reconstruction of the bases of strategies for the development of the management potential of teams in the conditions of network interaction were used.

\subsection{Experimental research base}

The Russian State Vocational Pedagogical University and 68 educational organization is the experimental base of the research.

\subsection{Stages of research}

The process of research and educational network development management provides for a specific sequence of actions, including conceptualization, programming its development process, planning the activity directions, development of individual innovation projects and managing the interaction of the network participants. The research was conducted in three stages:

- The first stage includes the theoretical analysis of the existing methodological approaches in the philosophical, psychological, pedagogical scientific literature and thesis works on the subject. In the course of the work, the problem has been highlighted, and the purpose and research methods, as well as a draft experimental research have been developed.

- The second stage includes the identification and substantiation of a set of pedagogical factors of effective interaction of network participants, the performance of experimental work, the execution of analysis, validation and refinement of the findings obtained in the course of experimental work.

- The third stage consists of the refinement of theoretical and practical conclusions, summaries and systematization of the results. On basis of the activity-based and professional-functional approaches in accordance with the goal set, methods of comparative theoretical and methodological analysis and theoretical reconstruction of bases of development strategies of the managerial potential of a modern educational entity under conditions of network interaction were applied.

\section{$4 \quad$ Results and Discussion}

Various approaches to determination of the managerial potential as an object of scientific research are actualized by development of the human potential [9], [34] as a source of the social capital [35] and the intellectual capital regarded as an important 
resource of development of socio-economic systems integrated in the human capital [12].

Let us remind that from positions of the professional-and-activity-based approach which is based on the interactive nature of managerial labour [17], [22], the managerial activity possesses a special objectness in capacity whereof the joint activity and activity of other persons act. Thus, addressing to the problems of network interaction in process of formation of unclassical forms of managerial activity is seen as adjusted and logical, as it actualizes needs of educational entities of various levels and of the whole educational system in the efficient self-determination and in the high-quality resulting development. It is known that the major problem emerging in course of a centralized translation of an advanced pedagogical experience is that of bureaucratization and the trend to scholasticism of the process [36], [37]. The time has passed, and the authoritarian-centralized system of management of innovations in education found itself in a dead-end, which resulted in its permanent crisis and arising of a new pedagogical ideology. One of the key content-based elements of the new approach is the idea that the number of the best samples of pedagogical activity in the real life of an educational entity is much higher than the number of those which can be assimilated and institutionalized by scientificmethodic structures in their officially acknowledged techniques. Audacious pedagogical search brings to life a lot of findings, while formal mechanisms of advanced experience translation lag behind these processes. So, principally new mechanisms of handling and translation of this experience are required. Let us note that the network-based and non-network managerial paradigms are incompatible ones in their essences. The non-network managerial paradigm is focused on clear goal-setting and advanced knowledge of what the interaction between educational organizations must and can lead to. So, the most important priority within non-network management is clear planning of the interaction results. Uncertainty and openness of the interaction results should be minimized. The interaction result should be calculated in advance with the maximum possible certainty. Thus, the non-network management model is oriented on linearity and certainty. The network-based model is quite another model in terms of the paradigm, as it is oriented on the principal uncertainty of interaction results as an essential value and on management under conditions of creative uncertainty. The highest sense of network interaction is an anthropo-practical contact, or a contact of anthropo-practices [38], as all successfully realized projects and techniques can be translated and adopted. Accordingly, the network-based managerial model is based on non-linear planning with preset absence of a clearly outlined configuration of the result. In this case, management is boiled down to creation of necessary organizational conditions for scientific, innovation and educational activity leading to emerging of results which cannot be definitely planned [22]. Knowledge inside a network community is distributed in a uniform manner, operation actions are jointly created and used, and it is defined which methods function better than others, how and when they can be applied in a more rational way. Such communities help their participants to develop their own professionalism and make valuable contributions into a common work. Uniting into a scientific-educational network can be regarded as a specially created form of expansion of the innovation cultural-educational space of the network interaction members wherein new types of activity and forms of interaction are elaborated and exchange of educational resources takes place in order to 
provide entirety, openness and possibility of self-development of the network interaction members, and new intellectual products are created. When we speak about development issues of scientific-educational networks, it is essential to mention that tangible assets in the modern life's conditions cease to be a source of an entity's competitive advantage, and this role is transferred to such intangible assets as the knowledge. Moreover, in purpose of developing of efficient mechanisms and tools of intensifying of external effects of the scientific-innovation activity in conditions of a scientific-educational network, accounting of peculiarities of the four knowledge types is of high importance [39]. The first type of knowledge is usually referred to the knowledge as a set of facts (know what). In this case, the knowledge is closest to the concept of "information" and can be split down and represented as units of information. The second type of knowledge is the knowledge as a reason or base which create a knowledge domain (know why). This type of knowledge directly relates to scientific knowledge. It lies in the base of technological developments of products and processes. Access to knowledge in this case occurs through elaborating of scientific and business contacts with scientists and other qualified personnel engaged in this sphere and through arranging of some joint activities, including scientific-research contracts. The third type of knowledge is the knowledge as a set of special abilities or skills to do something (know how). First, these are professional qualifications and acquired practices. Usually such type of knowledge is restricted within one entity only wherein it is "known well how to do" in their own way. To develop the network cooperation in the scientific-innovation sphere, it is very important that this type of knowledge be open and accessible within the network structure, at least. The fourth type is the knowledge which identify an individual carrier (know who). This type of knowledge includes the information about who possesses and master's knowledge and acquired practices and what these knowledge and practices are. This type of knowledge also includes a set of social interactions allowing to have access to certain experts and efficiently use their professional properties. It is extremely critical that an entity should possess such knowledge for its successful activity. Such knowledge are of internal nature and less subject to informational exchange between various entities, especially in a competitive environment. In other words, data about personalities are a kind of informational capital of any organization.

It should be emphasized that knowledge of the first two types are fully reproducible, i.e. can be obtained by assimilating of information from relevant sources in process of being educated, from books, magazines, online resources and so they can be considered as belonging to codified knowledge. Information technologies considerably simplified systematization and transferring of codified knowledge on any distances at minimum costs [40]. Thus, codified types of knowledge are easily reproducible, can acquire a commodity form and be represented on appropriate markets of scientific, technological, patent-based and other information and also be a central component of educational services. Production of codified types of knowledge is of the collective character, and the knowledge may be distributed by means of network-based technologies. Knowledge of the third and fourth types can be obtained through practical activity only. Know-how are usually obtained at transferring of professional habits from a master to a student. A know-how is a product of social interactions between scientists, experts and organizations, including interactions with contractors, consumers and competitors. These arrays 
of knowledge cannot be transferred via formalized information channels. Thus, the knowledge of the two last types form unformalized practical habits and abilities and belong to the so-called implicit knowledge. It is created in course of formal and informal network interactions intra-group, intra-company, inter-group, inter-institutional, cooperative, plus competitive ones. Moreover, implicit knowledge are practically devoid of the capability to acquire a commodity form (except for production know-hows which are legally defensed) and are nor reproducible. At the same time, the value of this or that expert can only be defined only by subjective assessments and expectations of a party which acquires appropriate expert services. The implicit knowledge, unlike the codified (explicit) one, much depends on the human factor. Their creation and transferring are only possible through individual practical interactions between a knowledge carrier and his/her pupil, and here a certain amount of conditionality of this process takes place, as there always remains a part of the implicit knowledge which is particularly individual and cannot be transferred at all. Within the scientific-educational network, in process of emerging of a new knowledge and practical experience, implicit and explicit knowledges are closely mutually conditioned for expert appraisals and distribution thereof between the interaction subjects for realization of innovative activity. Implicit knowledge is acquired in a practical activity for application of codified knowledge. Without practical application, codified knowledge is just a set of data devoid of any value. In turn, implicit knowledge does not exist without attempts to use the codified information. It emerges on the phase of teaching of a network subject, i.e. at assimilating of the codified knowledge by them, and develops in process of application of this codified knowledge in a professional activity. That is, the basic functional destination of the scientific-educational network is creation of totality of conditions and mechanisms for providing of self-organization and self-development of the innovation activity subjects, including development of the interaction participants' managerial potential. This is the case of a new approach to management of developing of educational and scientific organizations in the interests of development, assimilation and promotion of certain innovations. Within such management paradigm, both an educational entity and a local network structure are regarded as open self-regulating systems possessing emergent properties (i.e. new, unique properties of the system which are not inherent to its elements) for managing whereof the knowledge and correct application of synergy principles are necessary in order to productively use the collective's managerial potential. In this case, the proactive managerial activity goes beyond functional duty boundaries, it is not regulated and is structured on principles of voluntary participation, being aimed at development of selforganization on basis of expansion of network interaction of educational organizations in the interests of development of collectives' managerial potential at the expense of growth of initiative approaches of the network interaction based on conscious mastering of the methodological culture by members of the scientific-educational network. Improvement of the methodological culture level of network interaction participants allows to provide assimilation and obtaining of various types of knowledge in course of joint activity, among them: 
- Formalized knowledge represented as theories, conceptions and technologies.

- Unformalized practical knowledge and experience which manifest themselves in activities of the innovation process participants.

- Knowledge and experience caused in course of an open ad-hoc dialogue.

Thus, in process of interchanging and increasing of knowledge and experience, a common language (thesaurus) and understanding of norms of professional interaction and professional subculture arrears in the scientific-educational environment. And it is mastering of the methodological culture which allows the interaction participants to realize efficient assimilation of new areas of theory and practice of education, thus developing independence in obtaining new knowledge due to necessity to solve newly emerging scientific-methodical and creative tasks in this sphere.

A peculiar feature of scientific-educational interaction as a modern approach to development of participants' managerial potential is correct organization of the social space: re-distributing tasks, delegating powers, development of horizontal links, formation of the united cultural field of entities' network interaction [22]. In framework of the network, crowd-sourcing projects are realized wherein individual participants will adopt roles of discussion activators and proposal moderators, the mentioned discussions and proposals being formed by the network interaction participants in course of strategic sessions, which contributes to transition of the proposal from the category of idea to that of managerial project [41]. The work on formation of the institute of network internal coaches, that is, active participants possessing super-functional possibilities contributing to teaching of the network's other participants on basis of insider information not accessible to external coaches. The internal coaching practice is developed the main moving force whereof is proactive teachers possessing expressed reflexive and communicative competences which are able to render assistance and support to their colleagues in solving complex tasks. The listed technologies create the basis for determining of additional roles with a high managerial potential level (Table 1).

Table 1. System of proactive managerial activity under conditions of network interaction

\begin{tabular}{|l|l|l|}
\hline \multicolumn{1}{|c|}{ Function } & \multicolumn{1}{|c|}{ Task } & \multicolumn{1}{|c|}{ Realization form } \\
\hline $\begin{array}{l}\text { Developing of communicative space of } \\
\text { network-based interaction }\end{array}$ & $\begin{array}{l}\text { Organizing of cross-functional interac- } \\
\text { tion }\end{array}$ & $\begin{array}{l}\text { Activation of network- } \\
\text { based communication }\end{array}$ \\
\hline $\begin{array}{l}\text { Expansion of information field of the sci- } \\
\text { entific-educational network }\end{array}$ & Knowledge exchange & Sharing \\
\hline $\begin{array}{l}\text { Work with "problem space" and "solu- } \\
\text { tion space" }\end{array}$ & Forming of the common vision & Moderation \\
\hline $\begin{array}{l}\text { Support to network interaction members } \\
\text { entific-educational network }\end{array}$ & Creation and developing of new ideas & Crowd-sourcing \\
\hline $\begin{array}{l}\text { Formation of needs in changes } \\
\text { Adaptation to uncertainty via expansion } \\
\text { of capabilities of border areas performing } \\
\text { communications with the external envi- } \\
\text { ronment of the network properly and of } \\
\text { interaction participants }\end{array}$ & Breaking clichés & Facilitation \\
\hline
\end{tabular}


The consequence of forming of the managerial potential of a scientific-educational network participants includes the following steps:

- Analysis of the state of innovation processes in educational entities and working-out of the managerial action system. The basic purpose of its conducting is studying of dynamics, scales, forms and efficiency of innovation development of participating organizations in retrospect. The analysis allows to find positive issues and negative trends and to elaborate managerial approaches on their accounting when forming development lines

- Working-out of managerial mechanisms of providing the competitive innovation conduct of interaction participants for a mid-tern perspective in course of strategic sessions

- Formation of innovative strategies of development of scientific-educational organizations, agreeing thereof in teams of timelines, resources and executors

- Assessment of development of managerial potential of participants and providing of efficient prompt corporate-level management of innovative development strategies within network interaction.

The professional-functional approach is used in the basis of rational distribution of tasks in assessment of development dynamics of the managerial potential. Distribution and systematization of duties of the network members allows to determine the share of responsibility of certain educational entities in process of innovative projecting and to find responsibility centres (or something of the kind) operating in framework of Coordination Council, the basic functions whereof are:

- Organizing of works aimed at generation and sampling of innovation developments

- Monitoring of strategic innovative focus points

- Methodological guide

- Considering and preparing of innovative projects for approval at Scientific council

- Finding of positive and negative deviations from affirmed focus points of innovative development.

Operating within Coordination Council are:

- Team for intensifying of innovative flurries of activity which ensures formation of intellectual capital of the network as intangible assets.

- Team for determination of strategic innovations which is responsible for selection of scientific ideas from the corporate competitiveness position.

- Team for assessment of innovative projects which works on formation of an innovative project portfolio and uniting of educational entities within a certain project

- Team for innovative potential increasing which is responsible for methodological support of realization of projects.

- Team for support of innovation processes among the tasks whereof is monitoring of the course of projects realization within the network. 
Thus, activities of working teams, which can be regarded as a kind of centres of network responsibility, contribute to development of the managerial potential of the interaction participants.

In general, let us single out the following items from basic tools for management of development of the managerial potential of the network interaction participants:

- Management of participants' self-development on basis of training and self-training.

- Realization of the system of measures aimed at projecting of a powerful organizational culture of participants.

- Creation of horizontal structures of management on basis of self-regulated temporary creative collectives and delegating a number of commissions to them.

- Expansion of application of claimed forms of motivation of the educational activity subjects.

- Developing of informational culture of the interaction participants, that is, ability to purposefully work with information available in the network and to use information technologies for obtaining thereof.

\section{Conclusion}

It should be stated in conclusion that the modern (unclassical) forms of managerial activity are connected with increasing of the role of network communication and a special content-based nature of the managerial effect, which changes the very mechanism of managerial functions realization from institutionally organized to joint functionally self-organizing. It is development of the managerial potential which can be regarded as an important resource for growth of activity efficiency of a modern entity which acts under conditions of development of competitiveness and uncertainty. We believe that managerial potential of educational entities' collectives in conditions of systemic activity of the scientific-educational network can successfully developed in integrative management technologies based on a new methodology focused on development of involvement of network interaction into solving of organizational issues, solving of strategic and tactic tasks under conditions of systemic activity of the scientific-educational network. Thus, the managerial potential realized in forms which correspond to strategic tasks of development of organizations under conditions of network interaction is a constantly developing and self-restructuring adaptive activity-based resource becoming an important source of extra managerial results. Development of the managerial potential of interaction participants within network interaction is provided via creation of additional managerial roles and solving of super-functional managerial tasks, which allows to change the nature of the managerial labour. And so, participants of network interaction possessing a high level of the methodological culture are able to consciously and independently solve managerial tasks belonging to the sphere of functional tasks other than the employee's duty in an educational entity assumes. 


\section{References}

[1] H. Martens, "Social Transformation, Self-organization at Work and Participation in Germany", In New Frontiers of Democratic Participation at Work, Routledge, 2018, pp. 205223. https://doi.org/10.4324/9781315198194-9

[2] A. K. Roy, P. Singh, and U. N. Roy, "Impact of rural-urban labour migration on education of children: A case study of left behind and accompanied migrant children in India", Space and Culture, India, vol. 2, no. 4, pp. 17-34, 2015. https://doi.org/10.20896/saci.v2i4.74

[3] W. Lin, "Exploring the convergence of the mobile learning mode in network environment and the traditional classroom teaching mode", International Journal of Emerging Technologies in Learning (iJET), vol. 12, no. 07, pp. 170-181, 2017. https://doi.org/10.3991/ijet. v12i07.7248

[4] J. Wang, "Application of Blending Learning Based on Network Learning Space in Teaching Design of Digital Art", International Journal of Emerging Technologies in Learning, vol. 14, no. 3, 2019. https://doi.org/10.3991/ijet.v14i03.10107

[5] O.S. Vikhansky, and A.I. Naumov, "The other" management: go-ahead times", The Russian Management Journal, vol. 2, no. 3, pp. 105-126, 2004.

[6] O.I. Genisaretsky, N.A. Nosov, and B.G. Yudin, "The Concept of Human Potential: Initial Considerations", the Man, vol. 4, pp. 5-17, 1996.

[7] E.V. Kondratyev, Theory and praxis of development of an entity's managerial personnel: monograph, Moscow: INFRA-M, 2012, p. 396.

[8] Convention on the Protection and Promotion of the Diversity of Cultural Expressions. Adopted by UN at General Conference on Education, Science and Culture on 20.10.2005. Official text. UNESCO. [Online]. Available: http://unesdoc.unesco.org/images/0014/00 1429/142919r.pdf [Accessed: Sept 11, 2018]. https://doi.org/10.1163/ej.9789004164543.1$\underline{760.38}$

[9] T.I. Zaslavaskaya, "The human potential in the modern transformation process", Social Sciences and Modern Times, vol. 1, pp. 13-25, 2005.

[10] S.K. Parker, H. M. Williams, and N. Turner, "Modeling the antecedents of proactive behavior at work", Journal of Applied Psychology, vol. 91, pp. 636-652, 2006. https://doi.org/10.1037/0021-9010.91.3.636

[11] R.M. Nizhegorodtsev, and S.D. Reznik, The human capital: Theory and praxis of management in socio-economical systems. Monograph, Moscow: INFRA-M, 2014, p. 290.

[12] M.A. Huselid, and J.E. Barnes, Human capital measurement systems as a source of competitive advantage school of management and labor relations department of human resource management, NJ: Rutgers University, 2003, p. 27.

[13] G. Capaldo, L. Iandoli, and G. Zollo, "A situationalist perspective to competency management", Human Resource Management, vol. 45, no. 3, pp. 429-448, 2006. https://doi.org/10.1002/hrm.20121

[14] Yu.D. Krasovsky, "Organizational diagnostics of socio-cultural processes of a company", Knowledge. Understanding. Ability, vol. 3, pp. 212-215, 2012)

[15] Ye.A. Klimov, "On certain requirements to the group subject of labour", Acmeology, vol. 2, pp. 93-101, 2003.

[16] J. Van Djik, The network society: Social aspects of new media, London: Sage, 2006, p. 191.

[17] A.L. Zhuravlev, and T.A. Nestik, Psychology of joint activity management: New lines of research, Moscow: The Russian Academy of Science, Institute of Psychology, 2010, p. 248.

[18] G.Y. Peshkova, and A.Y. Samarina, "Digital economy and recruitment potential: strategical interconnection and prospects", The Education and science journal, vol. 20, no. 10, pp. 5075, 2018. https://doi.org/10.17853/1994-5639-2018-10-50-75 
[19] H. Mintzberg, "Third generation management development", Training and Development, vol. 58, no. 3, pp. 28-38, 2004.

[20] P. Drucker, Management Challenges for XXI century, NY: Harper Business Press, 2001, p. 224.

[21] T.E. Evtodieva, N.N. Davydova, S.V. Videneeva, and V.A. Fedorov, "The Concept of Network Organization and Design of Networks in Logistics", International Journal of Economic Perspectives, vol. 10, no. 3, pp. 75-82, 2016.

[22] N.N. Davydova, A.A. Simonova, and S.L. Fomenko, "How to Manage Development of Pedagogical Educational Cluster in Regional Space?", The European Proceedings of Social \& Behavioural Sciences (EpSBS), vol. XXXV, no. 32, pp. 281-289, 2018. https://doi.org/10.15405/epsbs.2018.02.32

[23] S.S. Kahai, and B.J. Avolio, Effects of leadership style and anonymity on the discussion of an ethical issue in an electronic meeting system context. Leadership at a distance: Research in technologically supported work, Mahwah, NJ: Lawrence Erlbaum Associates, 2008, pp. 513-538 https://doi.org/10.4018/978-1-59904-937-3.ch040

[24] N.N. Davydova, E.M. Dorozhkin, and V.A. Fedorov, "Objectives and Managing Model of Development of Research and Education Networks", The European Proceedings of Social \& Behavioural Sciences (EpSBS), vol. XXXV, no. 31, pp. 273-280, 2018.

[25] E. Sjostrand, and J. Santberg, Invisible management: The social construction of leadership, London: Cengage, 2002, p. 280.

[26] G.Ph. Hodgkinson, and P.R. Sparrow, The Competent Organization: A Psychological Analysis of the Strategic Management Process (Managing Work and Organizations), Philadelphia: Open University Press, 2002, p. 432.

[27] L. Crevani, M. Lindgren, and J. Packendorff, "Shared leadership: A postheroic perspective on leadership as a collective construction", International Journal of Leadership Studies, vol. 3, no. 1, pp. 40-67, 2007.

[28] N.N. Davydova, E.M. Dorozhkin, and V.A. Fedorov, "Innovative process development in the framework of scientific educational network: Management model", Naukovyi Visnyk Natsionalnoho Hirnychoho Universitetu, vol. 5, pp. 157-163, 2016.

[29] K. Van der Heijden, and E. Eden, the theory and praxis of reflective learning strategy making. Managerial and Organizational Cognition: Theory, Methods and Research, London: Sage, 1998, pp. 58-76.

[30] A.V. Tomiltcev, and A.V. Maltsev, "The problems of professional training assessment: methodological approaches", The Education and science journal, vol. 20, no. 4, pp. 9-33, 2018. https://doi.org/10.17853/1994-5639-2018-4-9-33

[31] W. Shi, L. Markoczy, and G. Dess, "The role of middle management in the strategy process: Group affiliation, structural holes, and tertius iungens", Journal of management, vol. 35, no. 6, pp. 1453-1480, 2009. https://doi.org/10.1177/0149206309346338

[32] A.S. Alexiev, J.J.P. Jansen, F.A.J. Van den Bosch, and H.W. Volberda, “Top management team advice seeking and exploratory innovation: the moderating role of TMT heterogeneity", Journal of Management Studies, vol. 47, no. 7, pp. 1343-1364, 2010. https://doi.org/ $\underline{10.1111 / \mathrm{j} .1467-6486.2010 .00919 . \mathrm{x}}$

[33] H. Prabowo, T. W. Cenggoro, A. Budiarto, A. S. Perbangsa, H. H. Muljo, and B. Pardamean, "Utilizing Mobile-based Deep Learning Model for Managing Video in Knowledge Management System", International Journal of Interactive Mobile Technologies (iJIM), vol. 12, no. 6, pp. 62-73, 2018. https://doi.org/10.3991/ijim.v12i6.8563

[34] A.B. Doktorovich, "Paradigm of socio-innovative development: the human potential and intellectual capital of socio-economic changes", Space and Time, vol. 1-2, no. 19-20, pp. 8490, 2015. 
[35] S. Durlauf, and M. Fafchamps, "Social Capital", Handbook of Economic. Amsterdam: Elsevier, vol. 1, no. 26, pp. 639-69, 2005.

[36] A.P. Usol'tsev, "Inflation of the competence-based approach in the Russian pedagogical science and practical teaching", The Education and science journal, vol. 1, pp. 9-25, 2017. (In Russ.) https://doi.org/10.17853/1994-5639-2017-1-9-25

[37] O.M. Gyshchina, and O.P. Mikheeva, "Massive open online courses for pedagogical staff training", The Education and science journal, vol. 19, no. 7, pp. 119-136, 2017. (In Russ.) https://doi.org/10.17853/1994-5639-2017-7-119-136

[38] V.I. Slobodchikov, "Activity as an anthropological category (on differences of the ontological and gnoseological status of activity)", Philosophy Issues, vol. 3, pp. 48-58, 2001.

[39] L. Edvinsson, and M. Malone, Intellectual Capital: Realizing Your Company`s True Value by Finding Its Hidden Brainpower, NY: Harper Business, 1997, p. 225.

[40] S. A. El-Seoud, H. El-Sofany, and I. Taj-Eddin, "Mobile Applications and Semantic-WebA case study on Automated Course Management", International Journal of Interactive Mobile Technologies (iJIM), vol. 10, no. 3, pp. 42-53, 2016. https://doi.org/10.3991/ijim. v10i3.5770

[41] N.A. Astashova, S.K. Bondyreva, and A.P. Smantser, "Development of the axiosphere of the future teacher in the dialogue space of modern education", The Education and science journal, vol. 20, no. 7, pp. 32-67, 2018. https://doi.org/10.17853/1994-5639-2018-7-32-67

\section{$7 \quad$ Authors}

Nataliia Davydova is a PHD in Technical Sciences. She is an Associate Professor, at Russian State Vocational Pedagogical University, Yekaterinburg, Russian Federation. davydova nataliia@bk.ru

Evgeniy Dorozhkin is Doctor of Pedagogy at Rector of Russian State Vocational Pedagogical University, Yekaterinburg, Russian Federation. edscience@,mail.ru

Vladimir Fedorov is Doctor of Pedagogy and Professor at Department of Vocational Education and Training Methodology at Russian State Vocational Pedagogical University, Yekaterinburg, Russian Federation.

Article submitted 2019-07-19. Resubmitted 2019-09-16. Final acceptance 2019-09-16. Final version published as submitted by the authors. 